\title{
In-silco investigation of EGFR network in kidney cancer: a drug discovery approach
}

Syed Umair Ahmad ${ }^{1 *}$, Amara Qadus², Basharat Ahmad ${ }^{1}$, Jalal Ahmad Khan $^{1}$, Zia Wali Shah ${ }^{3}$, Aamir Saeed ${ }^{1}$, Hamza Ali Khan ${ }^{1}$ and Tariq Mahmood $^{1}$

1. Department of Bioinformatics, Hazara University Mansehra, Pakistan

2. Department of Bioinformatics and Biotechnology, International Islamic university Islamabad-Pakistan

3. Centre for Human Genetics, Hazara University Mansehra, Pakistan

*Corresponding author's email: ahmadumair927@gmail.com

Citation

Syed Umair Ahmad, Amara Qadus, Basharat Ahmad, Jalal Ahmad Khan, Zia Wali Shah, Aamir Saeed, Hamza Ali Khan and Tariq Mahmood. In-silco investigation of EGFR network in kidney cancer: a drug discovery approach. Pure and Applied Biology. Vol. 9, Issue 2, pp1583-1595. http://dx.doi.org/10.19045/bspab.2020.90166

\begin{tabular}{llll}
\hline \hline Received: 23/12/2019 & Revised: 26/02/2020 & Accepted: 09/03/2020 & Online First: 18/03/2020 \\
\hline
\end{tabular}

\section{Abstract}

Epidermal growth factor receptor (EGFR) gene plays an important role in the cell membrane including cell cycle promotion and differentiation. In many cancers studies the EGFR alteration causes the development of Oncogenesis that promote carcinogenesis and metastasis. Aim of the current study is to better understand the EGFR protein-protein interacting network in kidney cancer to identifying co-targets for drug designing. EGFR protein was as a query in STRING database and a network of 34 nodes and 123 edges was extracted. HUBBA analyzer was applied for the identification of hubs protein in the network that showed the functional association among network components. The findings of this study explored five clusters which has intra/inter-modular connections those are targeting links in therapeutic strategy. The cbioportal cancer database was used to analyze the expression levels of gene encoding hubs protein in the network and their participation in kidney cancer. In total of twenty hub proteins, seven genes, including HRAS, SHC1, PTPN1, PIK3CB, HBEGF, NRG2, AGTR1 shows overexpression and five genes like PIK3CD, ARRB1, NRG1, RAB5A, EPN1 displayed under-expression in kidney renal cell carcinoma. Outcomes of the research declared novel components mutations, mediated through EGFR signaling that are involved in ATM, MAPK, MDM2, ATK/VEGFR signaling pathways of proliferation and anti-apoptotic activities. It is evident that experimental validation of this results could be employed for the identification of new diagnostic markers for kidney cancer.

Keywords: Carcinoma; Cbioportal; EGFR; Kidney cancer; String database

\section{Introduction}

Cancer is the phenomenon to give an explanation for the irrational condition of uncontrolled cellular growth. Asian countries have a shocking rate of cancer [1], and Kidney cancer is placed as the 9th most common cancer within the globe. Patients treated via dialysis for end stage renal disease (ESRD) are at high risk of many cancers, in particular the ones of the kidney and urinary tract. These organs can also be vulnerable to systemic carcinogenic, which includes those as a result of the biochemical and immunologic changes that arise with renal 
failure [2]. Amongst renal tumors, renal mobile carcinoma is one of the most frequent prognosis with approximately $90 \%$ and occurring in adults. Although no real information for the superiority of renal cellular carcinoma in Pakistan has been reported apart from Aga Khan University Hospital, Karachi on 2393 instances of solid malignancies confirmed a frequency of $1.8 \%$ amongst adult males [3].

Renal failure happens when the kidneys suddenly grow to a condition, not able to filter out waste products from the blood ensuing to accumulation of risky tiers of wastes and the blood's chemical makeup can also get out of balance [4].

Epidermal Growth Factor Receptor (EGFR) gene is located on chromosome $7 \mathrm{p} 12$ and codes for $185-\mathrm{kD}$ transmembrane tyrosine kinase [5]. Which performs a critical role in the malignant cell growth [6]. In renal cell carcinoma (RCC), the usage of immunohistochemistry (IHC) has mentioned frequencies of extended EGFR expression among 50\% and $90 \%$ [7]. The prognostic significance of EGFR overexpression in RCC with recognition to each survival and ailment-unfastened duration stays debatable [8]. Genetic changes, overexpression and constitutive activation of EGFR had been regularly reported in human stable tumors of breast, colon, kidney and prostate cancers [9]. Bioinformatics applies Insilco methods to find out gene loci, predict the transcripts of a particular gene or structure and location of a particular protein inside cell and the disease(s) associated with the abnormal structure or function of that particular protein. It also involves devising the effective drug designing strategy relative to a particular protein involved in a disease pathway [10]. Aims of the current study were to investigate the EGFR protein-protein interaction (PPI) signaling pathway and identify therapeutic drug design targets using various computational approaches.

\section{Materials and methods} Bioinformatics software and tools

Different tools and databases of bioinformatics were applied to extract the protein-protein interaction network of EGFR from STRING database. The Gene ontology (GO) enrichment analysis was performed and mapped to analyze the data of network with kidney cancer datasets.

Retrieval of EGFR PPI network by STRING database

STRING (Search Tool for the Retrieval of Interacting Genes/Proteins) a biological database, was used for retrieving the biological network. String contain predicted and known PPI interaction. The string contains experimental data, computational data and public text data and are freely available source database which is update regularly. The resource also focuses on function enrichment in user provided protein list. The latest version contains more than 9.6 million proteins from more than 2000 organisms

\section{Hub identification}

The file was downloaded in PSI -XML format from String database and were upload to HUBBA analyzer for identification of hub proteins in EGFR network by using double screening method.

\section{Cancer dataset analysis by using cBio portal}

An online cancer database, Cbioportal was used to explore, analyzed and visualize the cancer data sets that integrates data on epigenectics, genetics, proteomics and transcriptomic base with the range of cell lines and tissues. The main characteristic of portal is to provide the graphical summary gene-level visualization.

\section{Results}

\section{Retrieval of EGFR PPI network}

EGFR PPI interacting network was retrieved from String Database using the EGFR protein as query and displayed a dense network of 101 nodes, 1122 edges, average nodes 22.2, 
average local clustering coefficients 0.665 , expected number of edges 345 and PPI enrichment p-value <10.e-16 (Fig. 1).

For better understanding of interactions, the k-mean cluster option in the string database were applied to divide the interacting network into 5 clusters. These clusters were composed of closely connected protein in the network. In PPI network clusters, the arrows show the positive action effects, the lines shows the negative effects and the balls shows the unspecified effects (Fig. 2).

\section{EGFR Protein-Protein Interaction Network meta-analysis}

The interaction network of EGFR contains some molecular function in which fifty proteins involved in receptor binding in which the chemical signal binds to its receptor, these signals may result from cellular/tissue. Eighty-one proteins of EGFR network are involved in protein binding which efficiency can be affected by the binding of drugs. The less bond drug is more efficient because that can travel more easily in the cell membrane. Ten proteins of the network were involved in the EGFR binding. The EGFR is found on the cell membrane which are associated to homodimers upon binding of its proper ligand. Thirty sex proteins are involved in the enzymes binding, in which for a molecular reaction, the subtract bind temporary with its active sites. Thirteen proteins of the network are involved in the growth factor receptor binding that is the first stay or stop in the cells where the signaling may flow for the cell differentiation and proliferation starts. Fifteen proteins are involved in the Kinase binding. Kinase are those enzymes used for the modification of other proteins by the addition of phosphate group with them for phosphorylation (Table 1).

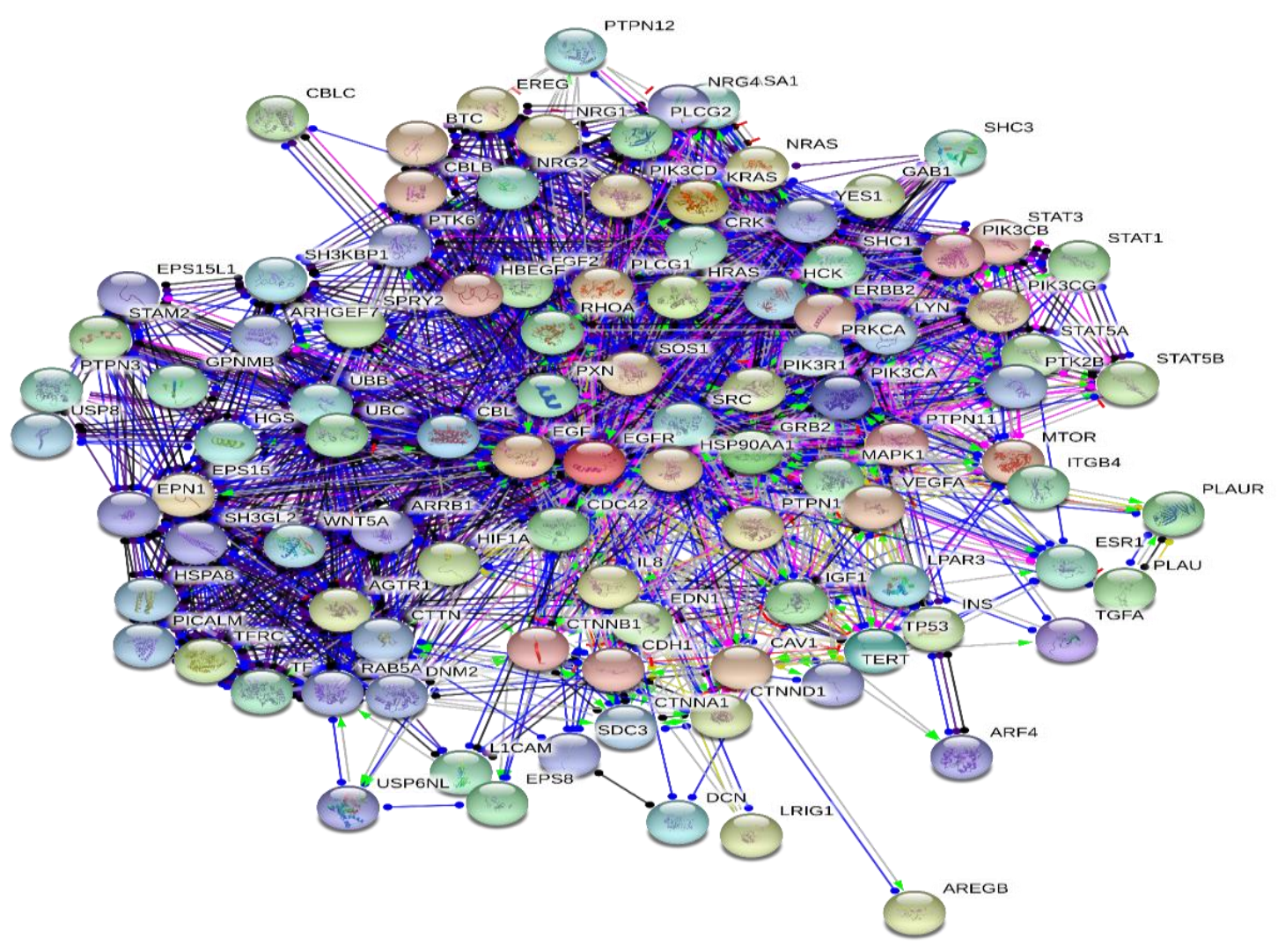

Figure 1. Shows EGFR PPI network that involved in signal transduction 


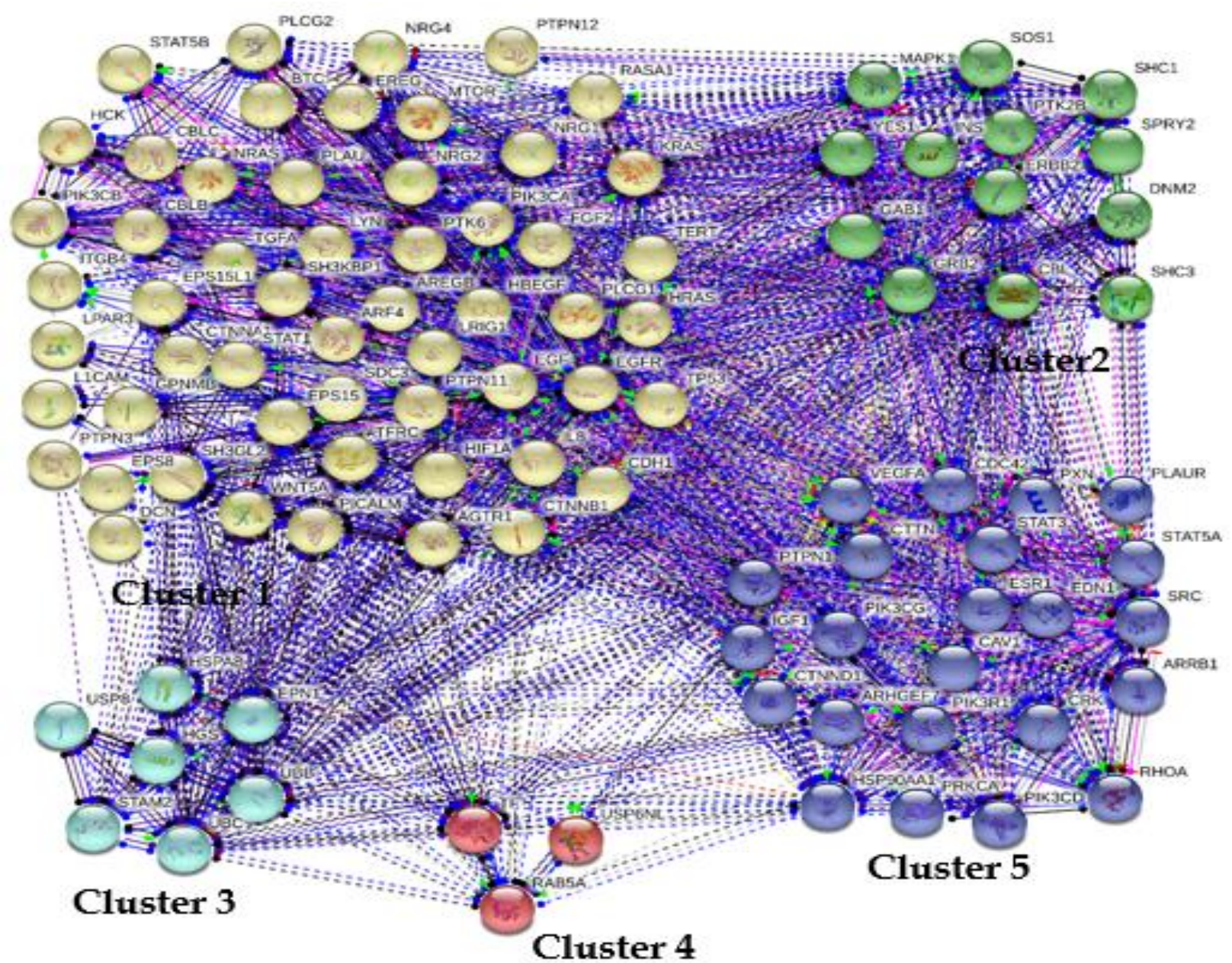

Figure 1. EGFR PPI network differentiated into 5 k-means clusters

Table 1. GO Molecular functions enrichment analysis of EGFR PPI network

\begin{tabular}{|c|c|c|}
\hline S. No. & Molecular function & No. of proteins \\
\hline 1. & Receptor binding & 50 \\
\hline 2. & Protein binding & 81 \\
\hline 3. & Epidermal growth factor receptor binding & 10 \\
\hline 4. & Enzyme binding & 36 \\
\hline 5. & Ephrin receptor binding & 7 \\
\hline 6. & Growth factor receptor binding & 13 \\
\hline 7. & Neurotrophin TRKA receptor binding & 4 \\
\hline 8. & Phosphatidylinositol-4, 5-bisphosphat kinase activity & $3-4$ \\
\hline 9. & Signaling adaptor activity & 7 \\
\hline 10. & Kinase binding & 15 \\
\hline
\end{tabular}

The enrichment analysis of protein-protein interacting network (PPI), has the significance of biological processes that involved the protein network such as EGFR signaling pathway. The EGFR activation leads to Homodimerization, 
heterodimerization, phosphorylation of specific tyrosine residues, and recruitment of several proteins at the intracellular portion of the receptors. Phosphorylation and activation of these two proteins on receptor binding lead to the initiation of signal transduction pathways, Enzyme linked receptor protein signaling pathway (Table 2). GO enrichment analysis identify the Extrinsic component of membrane, cellsubstract junction $\mathrm{n}$, cytosol, focal adhesion (Table 3).

GO enrichment analysis identify the proteins of network into KEGG pathways such as ERBB signaling pathway which contained four receptor tyrosine kinase which are structurally associated to EGFR which was for the first time discovered in membrane, some protein of the network involved in proteoglycans in cancer that contributed to biology of various types of cancer, different pathways in cancer (Table 4).

EGFR PPI STRING database pathway analysis exposed some signaling pathways that contain some protein in $\mathrm{SH} 2$ domain and SH3 domain (Table 5).

\section{Hubs protein identification}

The EGFR protein-protein interaction network was downloaded as an xml file in Protein Standards Initiative (PSI) format from the STRING database. The xml file was uploaded to HUBBA-HUBBA (http://hub.iis.sinica.edu.tw/Hubba) which is an online source Network visualization software applied for the identification of hubs protein in PPI network data. The double screening scheme method was used to analyze the EGFR PPI network. For the topological properties HUBBA identified twenty hubs protein in EGFR network (Fig. $3)$.

Table 2. GO Biological Process enrichment analysis of EGFR PPI network

\begin{tabular}{|c|c|c|}
\hline S. No. & Biological process & No. of proteins \\
\hline 1 & Epidermal growth factor receptor signaling pathway & 47 \\
\hline 2 & Transmembrane receptor protein tyrosine kinase signaling pathway & 62 \\
\hline 3 & Enzyme linked receptor protein signaling pathway & 64 \\
\hline 4 & Fc receptor signaling pathway & 35 \\
\hline 5 & Response to wounding & 45 \\
\hline 6 & Wound healing & 43 \\
\hline 7 & Fibroblast growth factor receptor signaling pathway & 31 \\
\hline 8 & Neurotrophin TRK receptor signaling pathway & 35 \\
\hline 9 & Movement of cell or subcellular component & 45 \\
\hline 10 & Blood coagulation & 34 \\
\hline
\end{tabular}

Table 3. GO Cellular localization enrichment analysis of EGFR PPI network

\begin{tabular}{|l|c|c|}
\hline S. No. & Cellular function & No. of proteins \\
\hline 1. & Extrinsic component of membrane & 18 \\
\hline 2. & Cell-substrate junction & 21 \\
\hline 3. & Cytosol & 62 \\
\hline 4. & Focal adhesion & 20 \\
\hline 5. & Cell junction & 27 \\
\hline 6. & Cell periphery & 68 \\
\hline 7. & Adherens junction & 19 \\
\hline 8. & Plasma membrane & 67 \\
\hline 9. & Plasma membrane & 20 \\
\hline 10. & Phosphatidylinositol 3-kinase complex & 6 \\
\hline
\end{tabular}


Table4. GO KEGG pathways enrichment analysis of EGFR PPI network

\begin{tabular}{|c|c|c|}
\hline S. No. & KEGG pathways & No of proteins \\
\hline 1. & ERBB signaling pathway & 34 \\
\hline 2. & Proteoglycans in cancer & 39 \\
\hline 3. & Pathways in cancer & 38 \\
\hline 4. & Glioma & 20 \\
\hline 5. & Focal adhesion & 24 \\
\hline 6. & Non-small cell lung cancer & 17 \\
\hline 7. & HIF-1 signaling pathway & 20 \\
\hline 8. & Prostate cancer & 19 \\
\hline 9. & Chronic myeloid leukemia & 19 \\
\hline 10. & Endometrial cancer & 16 \\
\hline 11. & Bacterial invasion of epithelial cells & 21 \\
\hline 12. & Chemokine signaling pathway & 24 \\
\hline 13. & MicroRNAs in cancer & 20 \\
\hline
\end{tabular}

Table 5. String pathway enrichment analysis of EGFR network

\begin{tabular}{|c|c|c|}
\hline S. No. & Pathway description & No. of proteins \\
\hline 1 & SH2 domain & 10 \\
\hline 2 & SH3 domain & 8 \\
\hline 3 & Protein kinase-like domain & 4 \\
\hline 4 & Phosphatidylinositol 3/4-kinase, conserved site & 4 \\
\hline 5 & Phosphatidylinositol 3-/4-kinase, catalytic domain & 3 \\
\hline 6 & Phosphatidylinositol 3-kinase adaptor-binding (PI3K ABD) domain & 7 \\
\hline 7 & Small GTPase superfamily, Rab type & 5 \\
\hline 8 & Tyrosine-protein kinase, active site & 5 \\
\hline 9 & Tyrosine-protein kinase, catalytic domain & 3 \\
\hline 10 & Phosphatidylinositol 3-kinase Ras-binding (PI3K RBD) domain \\
\hline
\end{tabular}

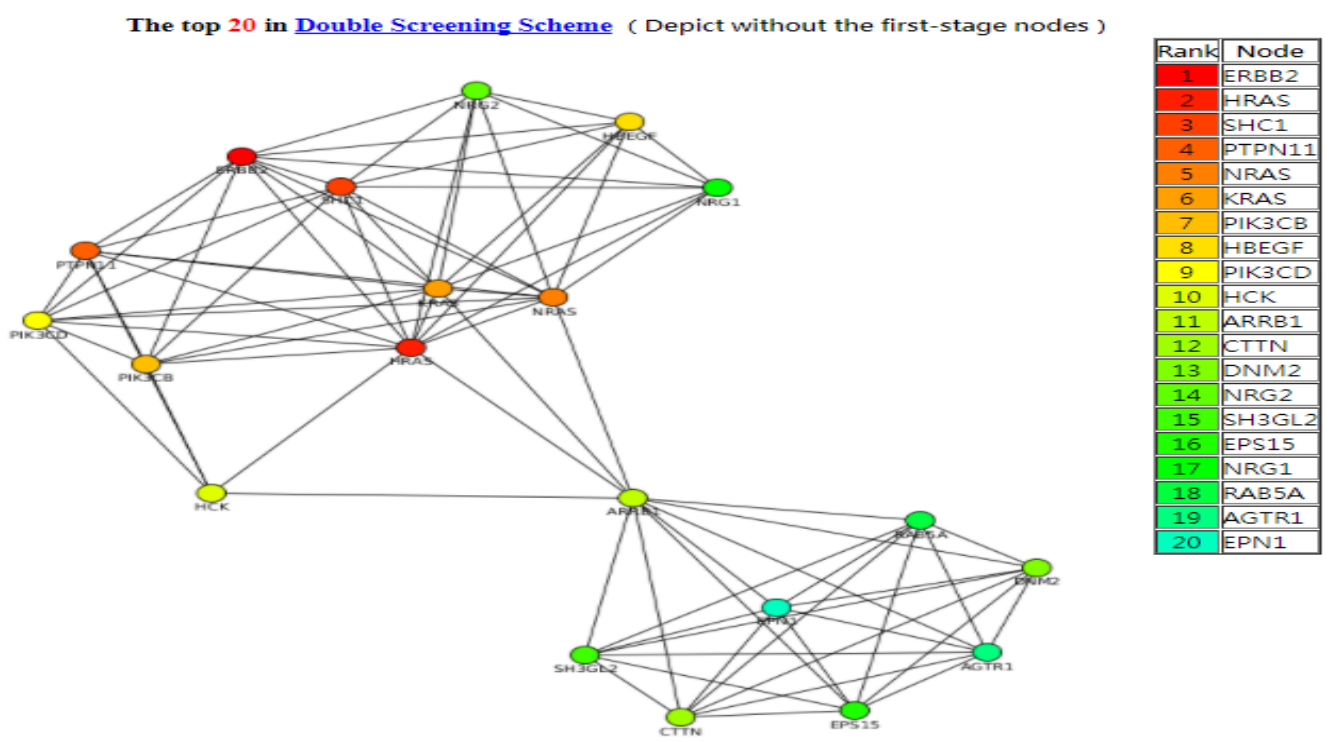

Figure 3. Hubs protein in network by using double scheming method on HUBBA-HUBBA 
The HUBS genes comparative analysis with Kidney cancer dataset

The cBioPortal cancer database, analysis of kidney cancer showed the significant disease connected genes, described their frequency, position and types of mutation to kidney cancer datasets. Cboipotral database showed different types of mutation including missense mutation, inframe mutation, truncating mutation, gene deletion and gene amplification as shown in (Fig. 4).

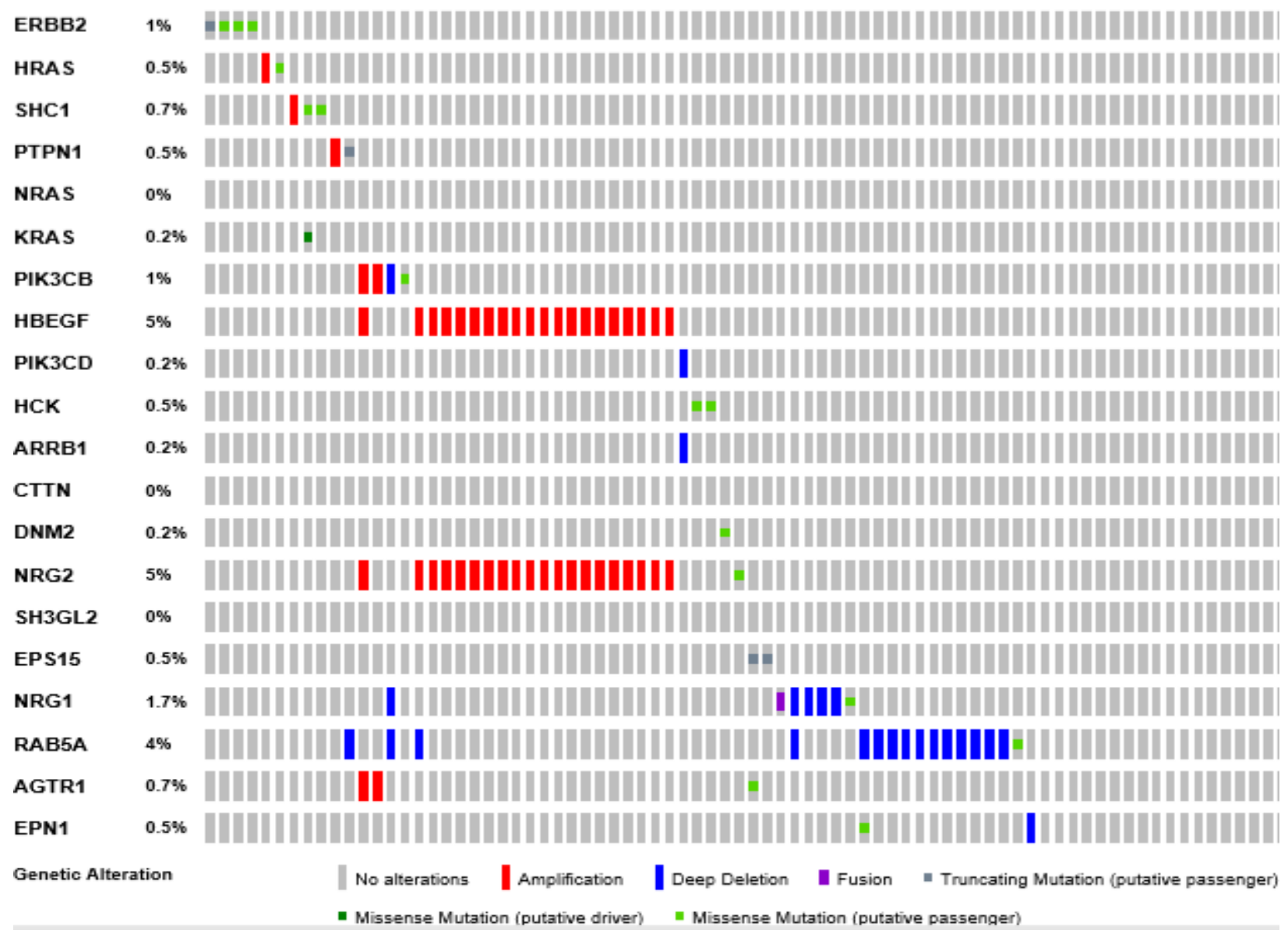

Figure 4. Kidney cancer relevant disease associated genes mutation result of Kidney renal cell carcinoma (TCGA, Nature 2013) dataset that has (418 patients / 418 samples) in which 418 showed alteration that is $14 \%$ of total dataset

The mutation tab in cBioPortal showed position, ratio and frequency of query gene and their mutation in the context of protein domain.

a) ERBB2 contain 633 amino acids which has $1 \%$ mutation that contain 4 mutations in which 3 missense and 1 truncating. b) HRAS contain 189 amino acids undergo only $0.2 \%$ mutation frequency that contain only one missense mutation. c). SHC1 contain total
583 amino acids which has $0.5 \%$ mutation frequency comprising only two missense mutation. d). PTPN1 containing 465 amino acid with Mutation Frequency $0.2 \%$ and has only 1 mutation of truncating. e). KRAS contain total 189 amino acids having mutation frequency of $0.2 \%$ which has 1 missense mutation. f). PIK3CB has total 1070 amino acids having mutation frequency of $0.2 \%$ which has 1 missense mutation. g). 
HCK has total 500 amino acids, of which mutation frequency is $0.5 \%$ and has 2 missense mutations. h). DNM2 has total 870 amino which undergo $0.2 \%$ mutation that contain 1 missense mutation. i). NRG2 has total 850 amino acids which undergo $0.2 \%$ mutation that contain 1 missense mutation. $\mathrm{j}$ ). EPS15 has total 896 amino acids which undergo $0.5 \%$ mutation that contain 1 truncating mutation. $\mathrm{k}$ ). NRG1 has total 640 amino acids which undergo $0.5 \%$ mutation that contain 1 missense mutation. 1). RAB5A containing 215 amino acids which undergo $0.2 \%$ mutation that contain 1 missense mutation. m). AGTR1 has total 359 amino acids which undergo $0.2 \%$ mutation that contain 1 missense mutation. $\mathrm{n}$ ). EPN1 has total 576 amino acids which undergo $0.2 \%$ mutation that contain 1 missense mutation (Fig. 5).

\section{ERBB2}

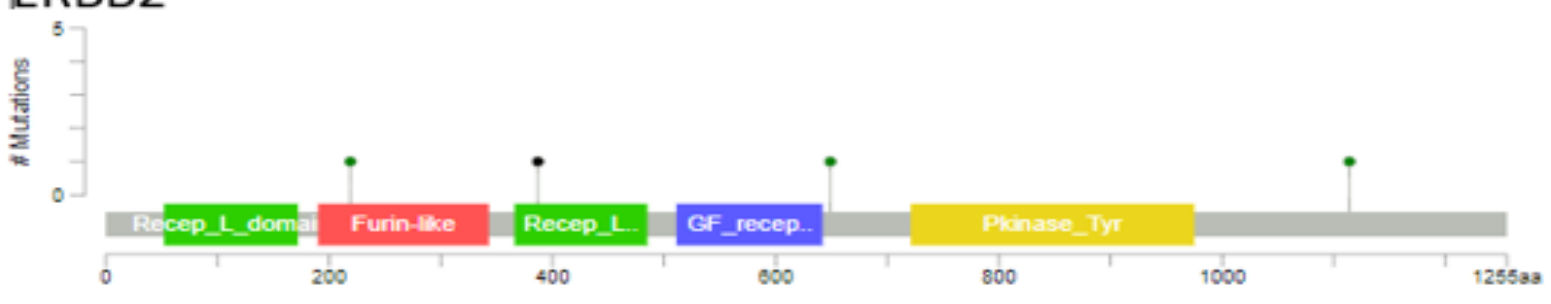

\section{HRAS}

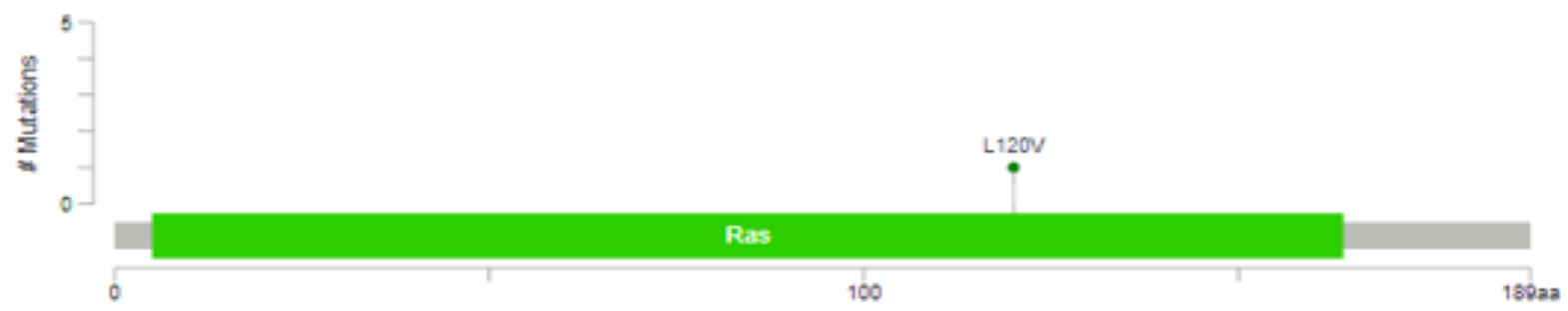

\section{SHC1}

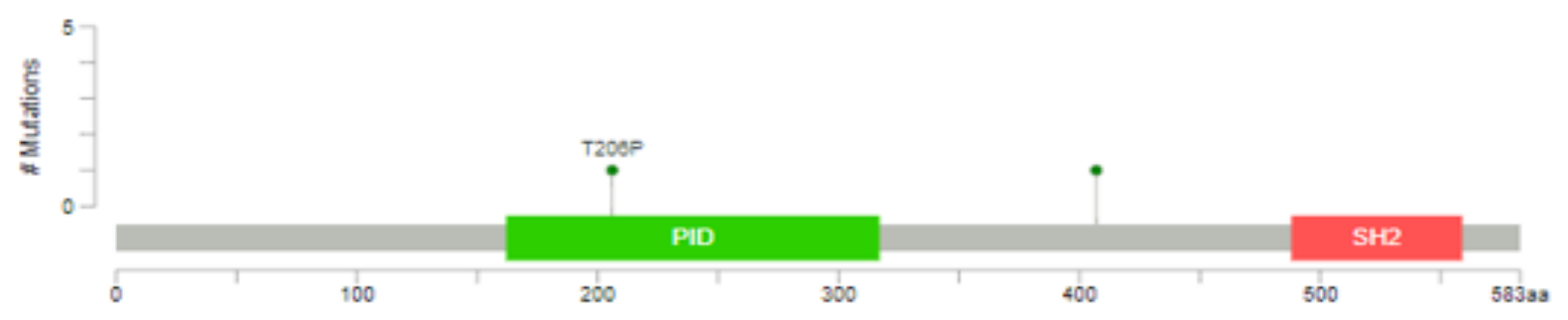


Pure Appl. Biol., 9(2): 1583-1595, June, 2020

http://dx.doi.org/10.19045/bspab.2020.90166

\section{PTPN1}
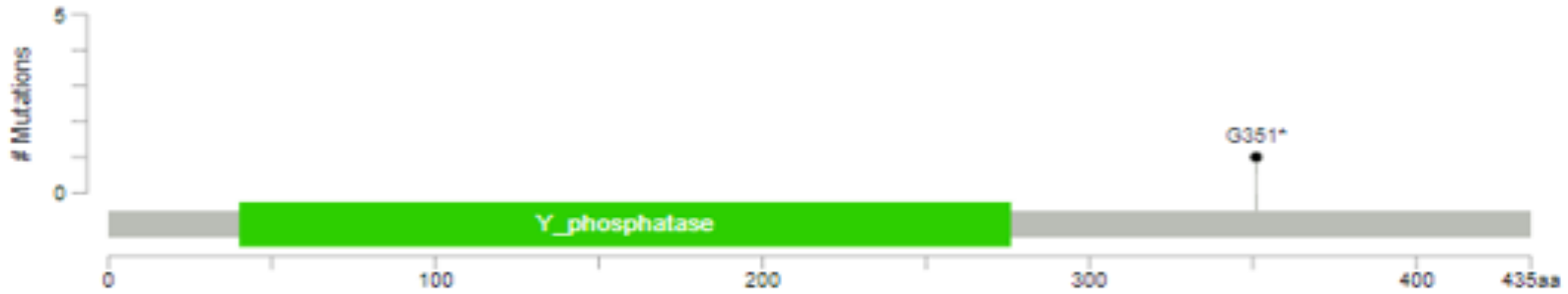

\section{KRAS}

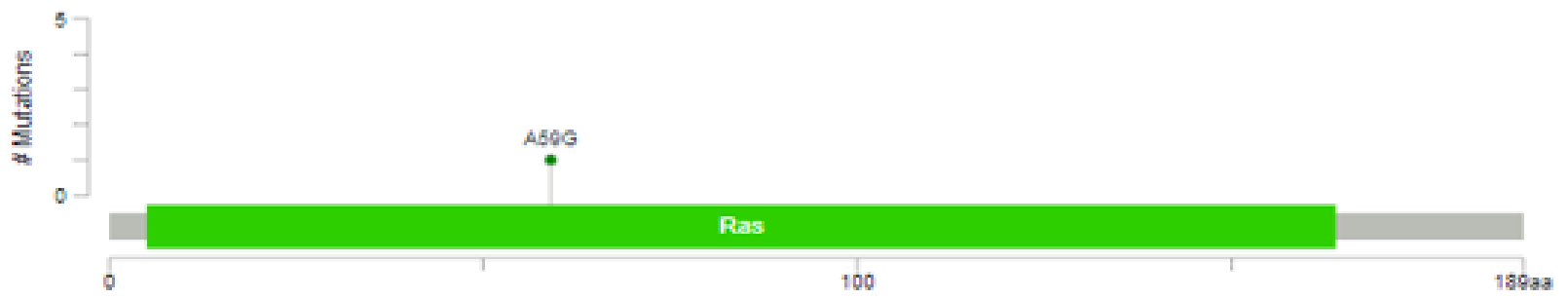

\section{PIK3CB}

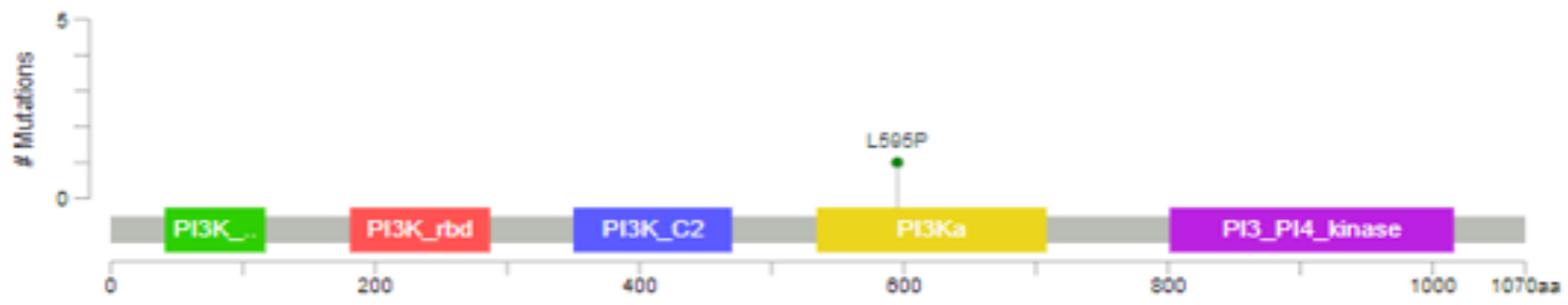

\section{HCK}
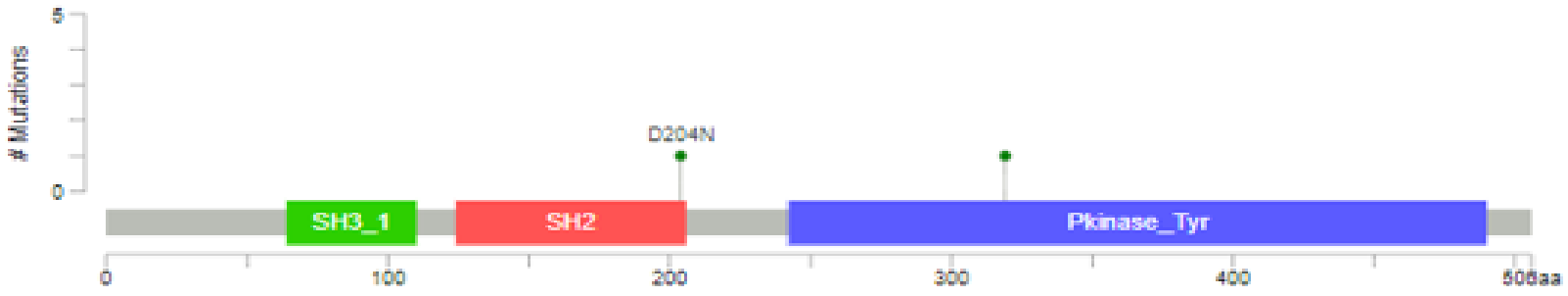

\section{DNM2}
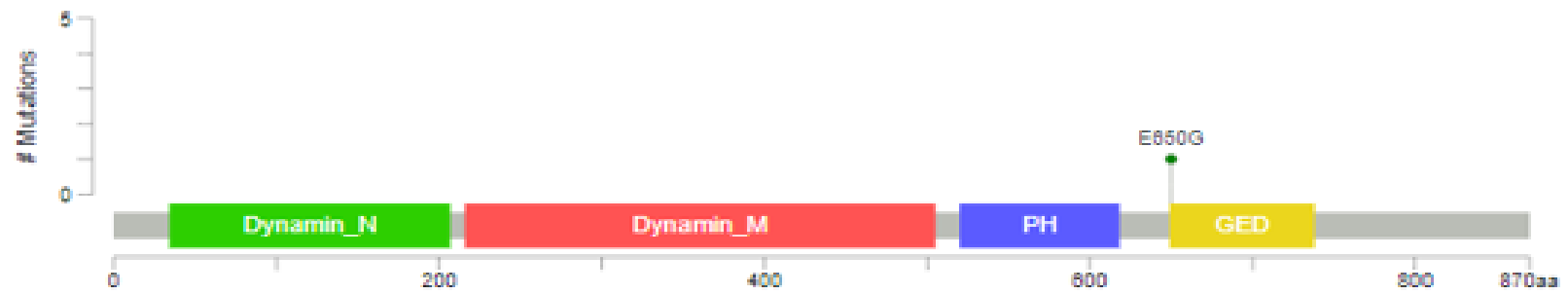

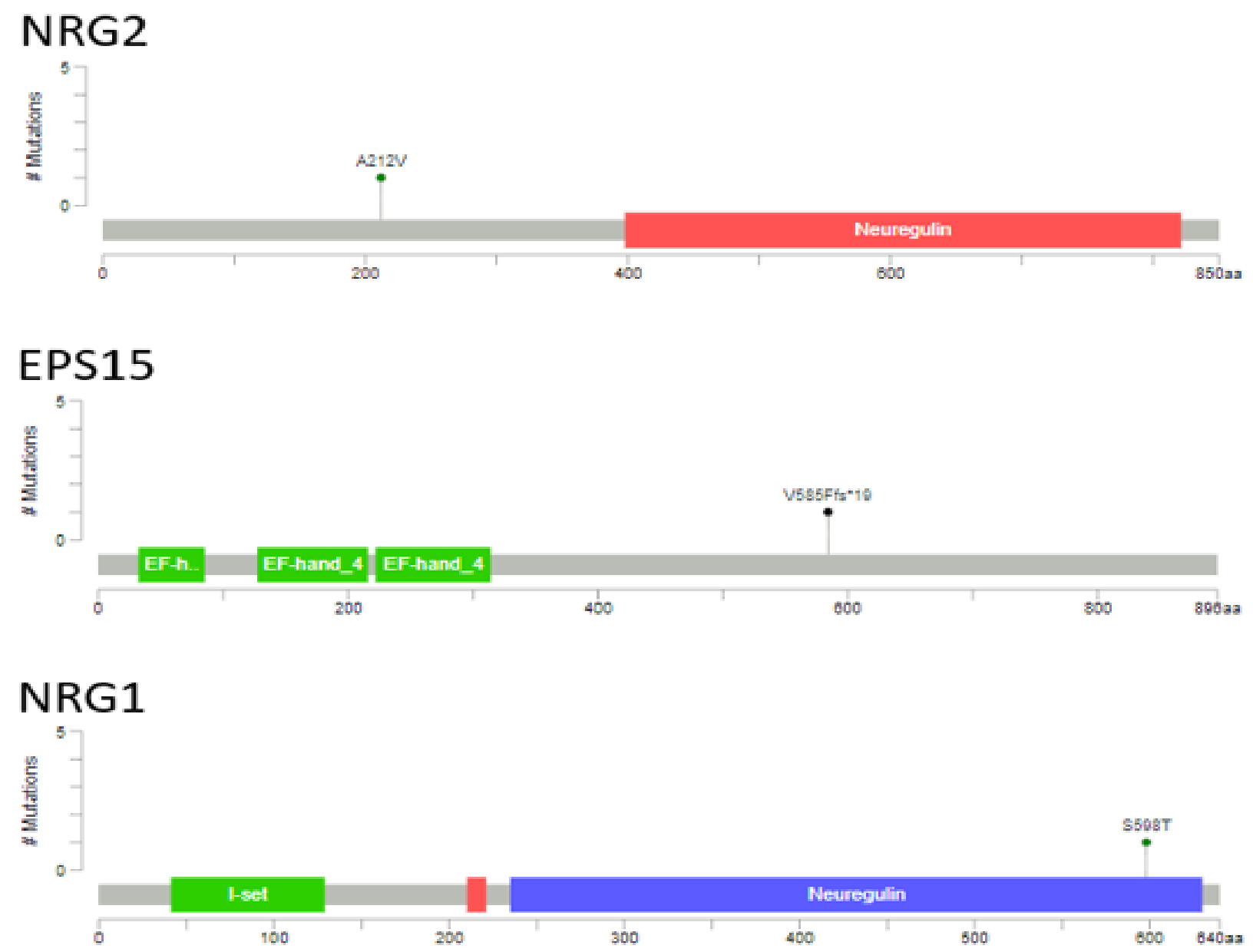

Figure 5. Displaying mutation (a) to (n)

\section{Discussion}

In this study, protein interaction network was investigated to recognize the hubs protein in the network. In EGFR network, 20 hubs protein were identified by analyzing using double screening scheme method. Each of the hubs has various interaction in the network. In current study we have obtained 5 clusters from protein interacting network, in which the cluster 1 , which is the biggest cluster contained much hubs proteins that are ERBB2 involved in growth factor, PTPN11 involved in the regulatory of cell growth, NRAS involved in somatic rectal cancer, KRAS responsible for activation of mutation, HCK help the receptor in activation, NRG2 included the growth and differentiation, SH3GL2, EPS15 involved in the pathways,
NRG1 help in cell to cell signaling, AGTR1 help in the regulation of aldosterone secretion, HBEGF diphtheria toxin receptor, PIK3CB involved in signaling pathways at outer membrane of the cell. Some of the hub's proteins in cluster 2 such as HRAS, SCH1and DNM2 are important in EGFR mediated signaling pathways. The cluster 3 contained some hubs that are PIK3CD, ARRB1 which are involved in the immune regulation and immune response and also contain CTTN which plays important role in regulating of the interaction among adherenstype junction and epithelia and carcinoma cell during apoptosis. The cluster 4 contained only one hub protein that is EPN1, which is involved in endocytosis of clathrin-coated vesicles. The cluster 5 in the network, 
contained only one hub protein that is RAB5A which is specific for its role in the regulation of EGFR

The epidermal growth factor receptor (EGFR) gene mutation has a key role in glomerular diseases and kidney injury which has been reported already [11]. Total 63 cancers were sequences for EGFR exon in which 21 mutation were reported and absorb that EGFR has $83.8 \%$ expression in clear cell carcinoma [12]. A few studies have been conducted related to association between stage of RCC and EGFR expression [13]. Some ligands of EGFR which are TGF-a, HB-EGF, EGF these ligand are also expressed in renal tubules which are reviewed in [14]. In previous studies, the ERBB2 amplification or over expression was approximately one third discovered in human breast cancer and connected with further tumors and poorer outcome [15]. Some other human tumor types also have been reported about the ERBB2 over expression or amplification which lead to lung cancer [16], also in gastric cancers [17], ovarian cancers [18], prostate cancer [19], and also lead to bladder cancer [20]. In present study we analyzed 3 mess sense mutation and one truncating in ERBB2. HB-EGF expression raised dominantly in gastric cancer, ovarian, breast cancer, glioblastoma, melanoma, in pancreatic cancers, prostate cancer, colon cancer and also in renal cell carcinoma. In our study, HB-EGF has shown amplification and over expression due to which there is uncontrolled division which lead to Kidney cancer. NRG2 is present in all type of human breast cancer and highly connected to biological aggressiveness of tumor reporter by [21]. In our result, out of 418 samples we observed that NRG2 showed high amplification that lead to kidney cancer. NRG1 is a protein which has a vital role in neuro inflammation and synaptic plasticity [22]. NGR1 has been constantly associated with the increased risk for schizophrenia
[23]. In our study we observed that NRG1 has only one missense mutation and absorb deep deletion.

Many previous studies have discovered that EGFR internalization and intracellular direction is RAB5A dependent and is attached to RAB5A activation [24]. From previous studies it is evident that RAB5A was overexpressed in stomach, lung and hepatocellular carcinomas. Recently, a set of observations found that RAB5A was overexpressed in lung, stomach and hepatocellular carcinomas [25], but the effect of RAB5A on the tumor cells is unclear. In our results the RAB5A showed deep deletion and one missense mutation that caused the kidney cancer. AGTR1 the angiotensin II receptor type 1 involved 10-20\% overexpressed in breast cancer independent patient chorts [26]. HRAS is located on chromosome $11 \mathrm{p} 15.5$ and a high conserved gene having genetic sequence variability existing in 3' hyper viable region between the other RAS family [27]. In the quarter of century about 100,000 of somatic mutation from the cancer have been reported since the first mutation was found in HRAS [28], in HRAS the heterozygous de novo germline mutation was identified by [29]. In the present study we absorbed the HRAS has $0.5 \%$ concentration of mutation which has only one missense mutation in the RAS domain that mediated the signaling pathways of EGFR that lead to kidney cancer.

\section{Conclusion}

The EGFR mediated intracellular signaling pathway controls intracellular interactions. PPI Network biology provide approaches for a better understanding of probable disease pathways. Protein interactions associated with disease are key actors of disease spreading mechanism and also their study has significance toward novel insights in disease investigation. In the current study, it was observed that EGFR connected signaling proteins are strongly interconnected with 
other proteins that participate in cell growth, apoptotic events and differentiation. In this study, the PPI network showed maximum interaction that activates EGFR signaling which leads to cells proliferation and neoplastic progress, resulting in kidney cancer. These significant interactions vigorously regulate the focus of therapeutic approaches on different EGFR signaling target proteins that regulate cell cycle. Few novel interactions were identified, HRAS, SHC1, PTPN1, PIK3CB, HBEGF, NRG2 and AGTR1 which shows apoptotic activities and proliferation and prove their participation in kidney cancer and proved to be significant in creating new therapeutic techniques.

\section{Authors' contributions}

Conceived and designed the experiments: SU Ahmad \& $\mathrm{T}$ Mahmood, Performed the experiments: A Qadus \& JA Khan, Analyzed the data: ZW Shah, B Ahmad \& A Saeed, Contributed materials/ analysis/ tools: SU Ahmad \& HA Khan, Wrote the paper: SU Ahmad \& A Qadus.

\section{References}

1. Mackay DJG, Boonen SE, Clayton-Smith J, Goodship J, Hahnemann, J.M.D, Kant S.G, Njølstad PR, Robin NH, Robinson DO, Siebert R \& Shield JPH (2006). A maternal hypomethylation syndrome presenting as transient neonatal diabetes mellitus. Hum Genet 120(2): 262-269.

2. Stewart JH, Buccianti G, Agodoa L, Gellert R, McCredie MR, Lowenfels AB, Disney AP, Wolfe RA, Boyle P \& Maisonneuve P (2003). Cancers of the kidney and urinary tract in patients on dialysis for end-stage renal disease: analysis of data from the United States, Europe, and Australia and New Zealand. JASN 14(1): 197-207.

3. Anwar Ul \& Haque AM (2008). Giant cell tumor of bone: a neoplasm or a reactive condition. Int J Clin Exp Pathol 1(6): 489.

4. Innis MA, Gelfand DH, Sninsky JJ \& White TJ (2012). PCR protocols: a guide to methods and applications. Academic press. Chaudhuri, AD et al. (2016). MicroRNA-7 regulates the function of mitochondrial permeability transition pore by targeting VDAC1 expression. J Biol Chem 291(12): 6483-6493.

5. Futreal PA, Coin L, Marshall M, Down T, Hubbard $\mathrm{T}$, Wooster R, Rahman $\mathrm{N}$ \& Stratton MR (2004). A census of human cancer genes. Nat Rev Canc 4(3): 81-90.

6. Maron BJ, Thompson PD, Ackerman MJ, Balady G, Berger S, Cohen D, Dimef R, Douglas PS, Glover DW, Hutter Jr AM \& Krauss MD (2007). Recommendations and considerations related to preparticipation screening for cardiovascular abnormalities in competitive athletes: 2007 update: a scientific statement from the American Heart Association Council on Nutrition, Physical Activity, and Metabolism: endorsed by the American College of Cardiology Foundation. Circul 115(12): 1643-1655.

7. Merseburger AS, Hennenlotter J, Simon P, Kruck S, Koch E, Horstmann M, Kuehs U, Küfer R, Stenzl A \& Kuczyk MA (2005). Membranous expression and prognostic implications of epidermal growth factor receptor protein in human renal cell cancer. Anticanc Res 25(3B): 1901-1907.

8. Minner S, Enodien M, Sirma H, Luebke AM, Krohn A, Mayer PS, Simon R, Tennstedt P, Müller J, Scholz L \& Brase JC (2011). ERG status is unrelated to PSA recurrence in radically operated prostate cancer in the absence of antihormonal therapy. Clin Canc Res 17(18): 5878-5888.

9. Allen NC, Bagade S, McQueen MB, Ioannidis JP, Kavvoura FK, Khoury MJ, Tanzi RE \& Bertram L (2008). Systematic meta-analyses and field synopsis of genetic association studies in schizophrenia: the $\mathrm{Sz}$ Gene database. Nat Genet 40(7): 827.

10. Fitzgerald JB, Schoeberl B, Nielsen UB \& Sorger PK (2006) Systems biology and combination therapy in the quest for clinical efficacy. Nat Cheml Biol 2(9): 458-466.

11. Amare PS, Varghese C, Bharde SH, Narasimhamoorthy NK, Desai S, Advani SH, Havaldar R \& Kulkarni JN (2001). Proliferating cell nuclear antigen and epidermal growth factor receptor (EGFr) status in renal cell carcinoma patients with 
polysomy of chromosome 7. Canc Genet and Cytogene 125(2): 139-146.

12. Anwar Ul \& Haque AM (2008). "Giant cell tumor of bone: a neoplasm or a reactive condition Inter J Clin Exp Pathol 1(6): 489.

13. Aoki Y, Niihori T, Kawame H, Kurosawa K, Ohashi H, Tanaka Y, Filocamo M, Kato K, Suzuki Y, Kure S \& Matsubara Y (2005). Germline mutations in HRAS protooncogene cause Costello syndrome. Nat Genet 37(10): 1038-1040.

14. Flamant M, Bollée $\mathrm{G}$, Hénique $\mathrm{C} \&$ Tharaux PL (2012). Epidermal growth factor: a new therapeutic target in glomerular disease. Nephrol Dial Transpl 27(4): 1297-304.

15. Gontan C, de Munck A, Vermeij M, Grosveld F, Tibboel D \& Rottier R (2008). Sox2 is important for two crucial processes in lung development: branching morphogenesis and epithelial cell differentiation. Devel Biol 317(1): 296-309.

16. Ishikawa J, Maeda S, Umezu KI, Sugiyama T \& Kamidono S (1990). Amplification and overexpression of the epidermal growth factor receptor gene in human renal-cell carcinoma. Inter J of Canc 45(6): 10181021.

17. Li B, Woo RS, Mei L \& Malinow R (2007). The neuregulin-1 receptor erbB4 controls glutamatergic synapse maturation and plasticity. Neuron 54(4): 583-597.

18. Li Y, Meng X, Feng H, Zhang G, Liu C \& Li P (1999). Over-expression of the RAB5 gene in human lung adenocarcinoma cells with high metastatic potential. Chinese Med Sci J= CHUNG-Kuo i Hsueh K'o Hsueh Tsa Chih (2): 96-101.

19. Mackay DJ, Boonen SE, Clayton-Smith J, Goodship J, Hahnemann JM, Kant SG, Njølstad PR, Robin NH, Robinson DO, Siebert R \& Shield JP(2006). A maternal hypomethylation syndrome presenting as transient neonatal diabetes mellitus. Hum Genet 120(2): 262-269.

20. Midgley RS \& Kerr DJ (2002). Ras as a target in cancer therapy. Critical reviews in Oncol/Hematol 44(2): 109-120.

21. Minner S, Rump D, Tennstedt P, Simon R, Burandt E, Terracciano L, Moch H, Wilczak W, Bokemeyer C, Fisch M \& Sauter G
(2012). Epidermal growth factor receptor protein expression and genomic alterations in renal cell carcinoma. Canc 118(5): 12681275.

22. Munafò MR, Yalcin $\mathrm{B}$, Willis-Owen SA \& Flint J (2008). Association of the dopamine D4 receptor (DRD4) gene and approachrelated personality traits: meta-analysis and new data. Biol Psychi 63(2): 197-206.

23. Nakagawa $T$, Hayase $Y$, Sasahara $M$, Haneda M, Kikkawa R, Higashiyama S, Taniguchi N \& Hazama F (1997) Distribution of heparin-binding EGF-like growth factor protein and mRNA in the normal rat kidneys. Kidney Inter 51(6): 1774-1779.

24. Nouwen EJ \& De Broe ME (1994). EGF and TGF- $\alpha$ in the human kidney: Identification of octopal cells in the collecting duct. Kidney Inter 45(5):1510-1521.

25. Zhao Z, Liu XF, Wu HC, Zou SB, Wang JY, Ni PH, Chen XH \& Fan QS (2010). Rab5a overexpression promoting ovarian cancer cell proliferation may be associated with APPL1-related epidermal growth factor signaling pathway. Canc Sci 101(6): 14541462.

26. Rhodes DR, Ateeq B, Cao Q, Tomlins SA, Mehra R, Laxman B, Kalyana-Sundaram S, Lonigro RJ, Helgeson BE, Bhojani MS \& Rehemtulla A (2009). AGTR1 overexpression defines a subset of breast cancer and confers sensitivity to losartan, an AGTR1 antagonist. Proce of the National Acad of Sci 106(25): 10284-10289.

27. Midgley RS, \& Kerr DJ (2002). Ras as a target in cancer therapy. Critical Rev in Oncol/Hematol 44(2): 109-120.

28. Revillion F, Lhotellier V, Hornez L, Bonneterre J \& Peyrat JP (2008). ErbB/HER ligands in human breast cancer, and relationships with their receptors, the biopathological features and prognosis. Annals of Oncol 19(1): 73-80.

29. Aoki Y, Niihori T, Kawame H, Kurosawa K, Ohashi H, Tanaka Y, Filocamo M, Kato K, Suzuki Y, Kure S \& Matsubara Y (2005). Germline mutations in HRAS protooncogene cause Costello syndrome. Nat Genet 1038-1040. 